cient for intranasal operations; indeed, the application must be very imperfectly made when this time is required. My patients complain of pain so very infrequently that I take it as a matter of fact that there will be no pain, and assure the patient so. In galvanocautery operations I seldom reach the fifteen minute mark for the completion of the operation, in. cluding the anesthesia. I very seldom have waited as long as fifteen minutes for anesthesia.

I always operate in the sitting posture, unless for special reasons I notice an idiosyncrasy or predisposition to fainting, because it is very much more convenient, the patient being able to expectorate and clear the nose in case of hemorrhage. While fainting and toxic effects are somewhat favored by the upright position, hemorrhage is less.

Dr. Anderson is correct in his statement that patients recover more quickly in the recumbent position, whether from the toxic effect of cocain or fainting. I have been compelled twice to place the patient in the recumbent position after having begun the operation sitting. It is not an easy matter to handle a limp patient under such condition; in fact, without an assistant it is at times quite impossible. This occasional unhappy condition in my opinion argues more than all else in favor of the recumbent posture, but the convenience both to patient and operator is certainly in favor of the sitting position.

Spraying the nose with a solution of cocain strong enough to produce anesthesia sufficiently complete for intranasal operations should be unconditionally and emphatically condemned as an unscientific and dangerous procedure.

The manner, then, of application as between placing pledgets of cotton saturated with a weak solution (6 to 10 per cent.) in the nasal cavity, and the method advocated by Dr. Anderson, and formerly practiced by myself, of a strong solu. tion ( 25 per cent.) to the saturated solution, I prefer the former method because I have found it much more convenient, saves time and is tolerated better by the patient, without increasing the dangers of the toxic effects of the drug.

HenRy W. Wa A

\section{On the Excretion of Urea.}

Tiverton, R. I., Sept. 10, 1897.

To the Editor:- On page 438 of the JournaL, Aug. 28, 1897, Dr. Charles Stover of Amsterdam, N. Y., is quoted as follows : "He also spoke of a case which came under his own observation, in which but 500 grains of urea were. excreted daily when there should have been 1,300 , the patient developing eclampsia."

I do not remember having read that pregnancy was a particular cause of increased excretion of urea, but consulting my authorities, quotations from a few enclosed, I learn that the normal excretion of urea is about 1 ounce or 500 grains in health. If the above statement of Dr. Stover is a fact, that she should have excreted 1,300 grains, or 2.15 time the normal amount during health, what cause should this great increase of the excretion of urea in pregnancy be ascribed to? Allow me to quote. Bartley ("Med. Chemistry," 4th Ed., 1895, p. 615): This quantity, multiplied by the number of fluid ounces passed in twenty-four hours, gives the amount of urea excreted in twenty-four hours, which should not be far from 500 grains. A less quantity than 350 grains in an adult, who is eating the usual amount, should be regarded as pathologic and suspicious of nephritis or deficient kidney excretion. Robert ("Urinary and Renal Diseases," 2d Ed., 1872, p. 115): The daily separation of urea, by adult men between the ages of 20 and 40 , averages about 500 grains; but the amount varies considerably from various causes, such as diet, exercise, meteorologic conditions and individual peculiarities; of twenty-four observations, of not less than six days each, tabulated by Dr. Parkes, the minimum result is 286.1 grains and the maximum 684.4 grains per day. Marshall ("Outlines of Physiology," Ed 1868, Lea, p. 777): In man, with an exclusively animal diet the daily quantity excreted was found by Lehmann to be about 820 grains ; with a mixed diet, 500 grains; with a vegetable diet 347 grains, and with a comparatively non-nitrogenous diet, 237 grains. In the female, from her smaller frame, her less active nutrient metamorphoses and the smaller quantity of food consumed, the daily quantity excreted is about three-fourths of an ounce (360 graing). Proportionately to the weight of the body it is less abundantly found in women. Hare ("Practical Diagnosis," 1896, p. 389): Although the quantity of urea varies very greatly in perfect health, the mean amount excreted in twenty-four hours by a healthy man of 20 to 40 years is about 512 grains; women excrete a little less than men. If, therefore, in a pregnant woman or a person suffering from Bright's disease, analysis shows a constant diminution in the amount of excreted urea, the physician is warned that a uremic convulsion or other manifestation of uremic disorder is imminent.

Nor can I find any reference in the standard works of my library to increased excretion of urea during pregnancy. On the other hand, I find many writers referring to eclampsia from other toxic causes than retained urea. (Vide, Professor Palmer, "Am. System of Obstetrics," p. 204, also Professor Lusk in his work, ) E. P. Stimson, M.D.

\section{Leprosy in Chinese Laundries.}

New York City, Sept. 6, 1897.

To the Editor:-The report of Charles F. Roberts, M.D. Sanitary Superintendent of the Board of Health of New York, to the Hon. Chas. G. Wilson, President, regarding the ques tion of the presence or absence of leprosy in the Chinese laun dries of this city, contains statements not consistent with the knowledge of the present day. I have nothing to say about the presence of the disease in the Chinese laundries; I may, however, say I do not believe in its existence. So far be is correct. But I object to his statement that "the authorities of the present day entertain the belief that the disease is due to infection not contagion.'

I venture to affirm that all able authorities of the whole world, believe in contagiousness, and that it is as contagious in "the four hundred of New York" as in the slums of Cherry Hill. "The best authorities of this country" do not agree with the report of the Medical Society of the County of New York, a report which was gotten up to back its chairman, Health Commissioner George B. Fowler, in his intent to discharge the lepers from North Brother Island. These lepers have since been let loose.

As a matter of expediency for the New York Board of Health that report of the New York County Medical Society, and this report on Chinese laundrymen, are of one piece.

Albert S. Ashmead, M.D.

\section{Reply to Dr. Paquin.}

Buffalo, N. Y., Aug. 26, 1897.

To the Editor:-I desire a little space to reply to an article of Dr. Paul Paquin written in criticism of my report, on treatment of tuberculosis, presented at the last meeting of the American Medical Association. Far from belittling the results of serum-therapy and declaring against the use of tubercle antitoxin, I am heartily in favor of such methods of treatment in suitable cases. The conclusions to which I came in regard to antitoxin are, it seems to me, thoroughly justified and are not materially different from Dr. Paquin's own con. clusions : viz., that "in cases of phthisis that are at all advanced it is of no value, that in the one case (and I particularly state one) of almost pure tuberculosis of larynx and upper lobe in which I used it, it was worse than useless, not having stayed 